\title{
Functional responses of three guilds of spiders: Comparing single- and multiprey approaches
}

\author{
Jacinto Benhadi-Marín ${ }^{1,2}$ (1) \\ José A. Pereira ${ }^{1}$ | José P. Sousa ${ }^{2}$ | Sónia A. P. Santos ${ }^{3,4}$
}

\begin{abstract}
${ }^{1}$ Centro de Investigação de Montanha (CIMO), Escola Superior Agrária, Instituto Politécnico de Bragança, Campus de Santa Apolónia, Bragança, Portugal

${ }^{2}$ Center for Functional Ecology, Department of Life Sciences, University of Coimbra, Calçada Martim de Freitas, Coimbra, Portugal

${ }^{3} \mathrm{CIQuiBio}$, Barreiro School of Technology, Polytechnic Institute of Setúbal, Rua Américo da Silva Marinho, Lavradio, Portugal

${ }^{4}$ LEAF, Instituto Superior de Agronomia,

Tapada da Ajuda, Lisbon, Portugal

\section{Correspondence}

Jacinto Benhadi-Marín, Centro de Investigação de Montanha (CIMO), Escola Superior Agrária, Instituto Politécnico de Bragança, Campus de Santa Apolónia, Bragança 5300-253, Portugal. Email: jbenma@hotmail.com
\end{abstract}

Funding information

Centro 2020, Grant/Award Number: Centro01-0145-FEDER-000007; Portuguese Foundation for Science and Technology, Grant/Award Numbers: EXCL/AGRPRO/0591/2012, SFRH/BD/97248/2013; Foundation for Science and Technology

\begin{abstract}
Spiders are successful natural enemies of pests occurring throughout the different strata of an agroecosystem. The study of their functional responses can provide information related to the potential effectiveness of different species and guilds on reducing a pest population. However, multiple prey availability may change the functional response of a predator. In this study, the functional responses of three species of spiders in single-prey and multiple-prey experiments were modelled. The spider species Haplodrassus rufipes, Araniella cucurbitina and Synema globosum were chosen as being representatives of ground runners, orb-weavers and ambushers, respectively. Three prey species were selected: a target prey, the Mediterranean fruit fly Ceratitis capitata and two alternate prey species, the flour moth Ephestia kuehniella and the house cricket Acheta domesticus. When the selected target prey C. capitata was supplied in the single-prey experiments, the most and the least efficient spider species were H. rufipes and S. globosum, respectively. However, opposite results were obtained when alternative preys were supplied. Also, A. cucurbitina significantly changed its functional response with the presence of alternative prey species. Considering the prey preference during the multiple-prey experiments, $A$. domesticus, used as representative of a heavy, long-sized and highly motile prey, was avoided whereas C. capitata, the target pest used as representative of light, small-sized and moderately motile prey was preferred by the three species of spiders. Ephestia kuehniella, used as representative of light, medium-sized and low motile prey was occasionally consumed. Each guild could include efficient predators against pests according to its hunting strategies and the ecological exploited niches. Orb-weavers could be efficient predators against flying pests; ambushers such as $S$. globosum could contribute to the reduction of the populations of flower-visiting pests, whereas active ground hunters may also play an important role preying on pests that develop a part or all of its life cycle in the ground. However, further research on feeding behaviour such as prey switching is needed for a better understanding of the effectiveness of spiders as natural enemies.
\end{abstract}

\section{KEYWORDS}

biological control, Ceratitis capitata, electivity, functional groups, overkilling 


\section{1 | INTRODUCTION}

Agroecosystems support a high diversity of arthropods with different functions (e.g., herbivores, omnivores and predators) (Altieri, 1999). Pest control ecosystem service can be exerted by natural enemies occurring throughout the different strata of the agroecosystem (e.g., canopy, soil or spontaneous vegetation). Spiders are among those natural enemies and, because they are extremely diverse (Turnbull, 1973; Uetz, Halaj, \& Cady, 1999), this diversity can be translated into guilds (i.e., groups of species using the same class of resources in a similar way) with different hunting strategies (Uetz et al., 1999).

Agroecosystems with multiple prey species allow predators to switch between prey species. Because spiders are generalist predators, their consumption of prey may depend on the density of the potential available prey species or can be driven by preference. A generalist predator switches between two prey species when they are provided together; it starts preying on the most abundant prey first, and continues attacking it until it is becoming rare (Murdoch, 1969). In the context of biological control, knowledge on prey preferences by a potential natural enemy is essential in evaluating its pest suppression success and for predicting predation in the field (Hassanzadeh-Avval, Sadeghi-Namaghi, \& Fekrat, 2018).

A common approach to investigate the potential of predators for biological control in terms of efficacy is the study of their functional response. The functional response of a predator-prey system is defined by the relationship between the number of prey eaten by one predator per certain time and the prey density (Jeschke, Kopp, \& Tollrian, 2002; Solomon, 1949). Factors such as different predator foraging strategies, prey handling and digestion time, prey escape or avoidance behaviour, alternative prey, resources, habitat structure and environmental conditions can actually change the functional response (Chan et al., 2017). Moreover, other parameters related to food intake such as digestion and energy management (e.g., energy budget and conversion factor) should be considered as well because the functional response may depend on them (Jeschke et al., 2002).

Digestion-limited predators process their prey items slower than they handle them (Jeschke et al., 2002). This fact could make spiders inefficient natural enemies; however, the consequence of this unbalance between digestion and handling times can be bypassed through a behaviour called overkilling, wasteful killing or unnecessary killing (i.e., killing without feeding or discarding partially consumed prey) (Johnson, Akre, \& Crowley, 1975).

Different guilds of spiders (see Cardoso, Pekár, Jocqué, \& Coddington, 2011; Uetz et al., 1999) such as wandering sheet/tangle weavers, ground runners and specialists proved to be successful natural enemies in laboratory against aphids, flies and ants, respectively, showing an amount of wasteful killing positively correlated with prey density (Mansour \& Heimbach, 1993; Pekár, 2005; Samu \& Bíró, 1993). Although the role of spiders as natural enemies has been already addressed following a functional response approach, the influence of multiple prey availability on the functional response of spiders has been largely neglected. Also, because of their great diversity, information on the feeding parameters and hunting behaviour of spiders is still extremely scarce especially in the context of biological control.

In this work, we aimed (a) to assess and compare the functional response of three guilds of spiders using both a single- and a multipleprey approach, (b) to investigate the potential of each functional group as natural enemies in terms of prey biomass suppression, (c) to calculate the prey preference of each functional group for different prey types and (d) to link the predator food preference to prey traits.

\section{2 | MATERIALS AND METHODS}

The selected species of spiders were Haplodrassus rufipes (Lucas, 1985) (Gnaphosidae), Synema globosum (Fabricius, 1775) (Thomisidae) and Araniella cucurbitina (Clerck, 1757) (Araneidae). All the species are generalist predators (Marc, Canard, \& Ysnel, 1999; Ajuria \& Reader, 2014; J. Benhadi-Marín, personal observation) and in this study they represent three functional groups according to their hunting strategies following Uetz et al. (1999). Haplodrassus rufipes is a nocturnal ground runner spider with a Mediterranean distribution that builds its nests under stones and uses them as shelters during the day (BenhadiMarín, J., personal observation) (body length female: $12.5 \mathrm{~mm}$ ) (Nentwig, Blick, Gloor, Hänggi, \& Kropf, 2018). Synema globosum is a palearctic ambusher species (body length female: 6.8-8 $\mathrm{mm}$ ) (Nentwig et al., 2018) that hunts insects on flowers during the day and nests under the flower or by joining two nearby flowers (Ajuria \& Reader, 2014). Araniella cucurbitina is an orb-weaver spider that ranges from Europe, Turkey, Central Asia to China and Korea and uses its orbicular web to hunt at different strata on vegetation (body length female: 4.5-9.5 mm) (Nentwig et al., 2018).

Three prey species were selected for the functional response experiments, a target prey and two alternative preys. The target prey was Ceratitis capitata (Wiedemann) (Diptera: Tephritidae) (body length: $4.88 \pm 0.09 \mathrm{~mm}$ [mean $\pm S E]$ ]), the Mediterranean fruit fly, that is a worldwide distributed harmful pest attacking more than 250 species and affecting economically relevant fruit crops (Weldon, 2014). This species was selected as model for a pest that uses different strata during its life cycle. Adults are free-living flying insects; the larvae feed on the fruit pulp and, once mature, drop to the ground, tunnel into the soil and pupate. Finally, the adult develops within the pupa and emerges towards the soil surface (Thomas et al., 2010). The two alternative prey species were the flour moth Ephestia kuehniella Zeller (Lepidoptera: Pyralidae) (body length: $6.90 \pm 0.10 \mathrm{~mm}$ [mean $\pm S E]$ ), and the house cricket Acheta domesticus (Linnaeus) (Orthoptera: Gryllidae) (body length: $9.52 \pm 0.18 \mathrm{~mm}$ [mean $\pm S E$ ]), as representatives of a flying prey and a soil-inhabiting prey species, respectively.

\subsection{Origin and rearing of spiders}

Immature spider females of $H$. rufipes, S. globosum and A. cucurbitina were individually hand captured in the municipalities of Mirandela and 
Bragança (northeast of Portugal) in early May 2016 and 2017. In total, near 150 individuals of each species were captured. Specimens of $H$. rufipes were searched under soil stones in an olive grove in Valbom-dos-Figos $\left(41^{\circ} 32^{\prime} 58^{\prime \prime} \mathrm{N} ; 7^{\circ} 08^{\prime} 44^{\prime \prime} \mathrm{W}\right)$, specimens of S. globosum were captured by inspecting flowers of Cistus ladanifer L. in a semi-natural shrubland area adjacent to an olive grove in Cedães $\left(41^{\circ} 29^{\prime} 17^{\prime \prime} \mathrm{N} ; 7^{\circ} 07^{\prime} 31^{\prime \prime} \mathrm{W}\right)$ and specimens of $A$. cucurbitina were captured by inspecting low sized pine trees around Bragança $\left(41^{\circ} 50^{\prime} 19^{\prime \prime} \mathrm{N} ; 6^{\circ} 44^{\prime} 49^{\prime \prime} \mathrm{W}\right)$ during the night.

The spiders were transported into the laboratory in perforated plastic tubes (volume - $15 \mathrm{~mL}$ ). Afterwards, specimens of A. cucurbitina and S. globosum were transferred individually into plastic Petri dishes $(5.2 \mathrm{~cm}$ in diameter and $1.2 \mathrm{~cm}$ height). The specimens of $H$. rufipes were individually placed into plastic cages $(7.7 \mathrm{~cm}$ in diameter and $4.3 \mathrm{~cm}$ height) and provided with an inverted $\mathrm{v}$-shaped filter paper strip ( $2 \mathrm{~cm}$ in length and $4 \mathrm{~cm}$ in width) to provide shelter.

Spiders were maintained in a climate chamber at $21 \pm 1^{\circ} \mathrm{C}, 70$ $\pm 5 \% \mathrm{RH}$ and a photoperiod of 16:8 (L:D) hr. Every week, half of a $2 \mathrm{~cm}$ sphere of sodium acrylate hydrogel was placed on the bottom of each Petri dish to provide water. Spiders were fed ad libitum to maturity with adults of $C$. capitata obtained from laboratory cultures maintained at the School of Agriculture of the Polytechnic Institute of Bragança since 2012 (Dinis, Pereira, Benhadi-Marín, \& Santos, 2016). Each spider was starved for 7 days prior to the functional response assays.

\subsection{Origin and rearing of prey}

Ceratitis capitata was selected to perform single-prey (non-choice) functional response assays, and two other prey species, E. kuehniella and $A$. domesticus, were used as alternative food in the multiple prey functional response assays. Moths were reared on a mixture of wheat bran and corn flour (3:1) half-filling 10 uncovered plastic beakers (1 L) that were maintained in two poly-methyl-methacrylate cages $\left(40 \mathrm{~cm} \times 30 \mathrm{~cm} \times 30 \mathrm{~cm}\right.$ ) under controlled conditions at $24 \pm 2^{\circ} \mathrm{C} ; 60$ $\pm 5 \% \mathrm{RH}$ and a photoperiod of $16: 8$ (L:D). Crickets were initially purchased from a pet shop, and maintained in the laboratory at $21 \pm 1^{\circ} \mathrm{C}, 70 \pm 5 \% \mathrm{RH}$. The cricket population was placed into a plastic box $(35 \mathrm{~cm} \times 25 \mathrm{~cm} \times 30 \mathrm{~cm})$ covered with a multiperforated cap. A layer of $2 \mathrm{~cm}$ in height of cat litter was provided as substrate. A plastic Petri dish (5.2 cm in diameter and $1.2 \mathrm{~cm}$ height) was placed at each box corner and filled with minced cat food as nourishment. Water was provided with 10 spheres of sodium acrylate hydrogel ( $2 \mathrm{~cm}$ in diameter) placed randomly on the litter surface.

\section{3 | Experimental arenas}

For functional response assays, three kinds of arenas were prepared according to each functional group of spiders. All the arenas were composed of a round plastic cage $(7.7 \mathrm{~cm}$ in diameter and $4.3 \mathrm{~cm}$ height) with a hole ( $1 \mathrm{~cm}$ in diameter) made in the lateral side of each cage and covered with a lid of a glass Petri dish ( $9 \mathrm{~cm}$ in diameter); each hole was closed with a cotton ball to facilitate the introduction of prey species. For A. cucurbitina, each arena was left empty because the spiders build their orb-web on the glass Petri dish. For S. globosum, an S-shaped paperboard strip $(2 \mathrm{~cm}$ width in the base, $3 \mathrm{~cm}$ in height and $2 \mathrm{~cm}$ width in the upper horizontal segment) was glued to the bottom of each cage in order to simulate a flower used as shelter. For $H$. rufipes an inverted v-shaped filter paper strip $(2 \mathrm{~cm}$ in length and $4 \mathrm{~cm}$ in width) was placed on the bottom of the cage in order to simulate a stone used as shelter.

\subsection{Functional response assays}

A total of 10 arenas for each initial prey density, one spider per arena and six initial prey densities ( $N=3,5,10,15,25$ and 40 individuals) were used to assess the single-prey functional response of each spider species fed on adults of $\mathrm{C}$. capitata. Assays were conducted at $21^{\circ} \mathrm{C}$ and $70 \pm 5 \%$ relative humidity and a photoperiod of 16:8 (L:D) hr. The flies were anaesthetised to facilitate manipulation by exposing them to diethyl ether (Panreac, Barcelona, Spain) for $20 \mathrm{~s}$ before being transferred into the arenas (once in the arenas, flies recovered their activity after $5 \mathrm{~min}$ on average). Each trial lasted $24 \mathrm{hr}$ after which the number of prey killed was recorded.

The multiple-prey functional responses were assessed by including two alternative prey species into each arena (E. kuehniella and A. domesticus) together with the target prey $C$. capitata. Ten arenas were used for each initial prey density and one spider per arena and per spider species. Increasing prey densities were given to the spiders maintaining the target prey: alternative prey ratio at $3: 1(N=3,6,10$, 15, 25 and 40 for $C$. capitata, and $N=1,2,3,5,8$ and 13 for E. kuehniella and $A$. domesticus) and the assays were conducted as explained above.

\section{5 | Prey biomass suppression}

The potential of spiders to reduce the biomass of prey in each arena was evaluated along with the single-prey functional response assays. Each spider was weighed before and after each trial. For each arena, two groups of flies were used. Each one contained the same number of individuals (i.e., initial prey density), one group was weighed accounting for the initial fresh weight of the prey (see Section 2.7.2.) and the other one was offered to the spiders. This was to avoid the introduction of dead flies (i.e., subjected to an excessive time of exposure to diethyl ether for weighing purposes) in the arenas. Once each functional response assay finished, the remains of the killed prey specimens in each arena were also weighed accounting for the remains of captured prey weight (see Section 2.7.2.).

\subsection{Spider food preference and prey traits}

The number of flies, moths and crickets killed by each spider species was recorded at each prey density after the multiple-prey functional response assays and the count of the number of killed individuals of each prey species was used to assess the spider's food preference. Three traits were selected for the prey species that could be related 
to the spiders food preferences: (a) the prey biomass, (b) prey body length as a representative trait for the hunting risk of predators and (c) the prey activity rate as a trait involved in the encounter rate. The fresh body weight was measured using a precision scale (RDWAG$\mathrm{XA} 52 / 2 \mathrm{X}, d=0.01 \mathrm{mg}$ ) and the body length (from the vertex to the most posterior part of the abdomen in dorsal view) using LAS software (Leica Microsystems Ltd. v.3.8.0.) with a Leica DFC295 camera mounted on a Leica MZ95 stereomicroscope (Leica Microsystems Ltd., Switzerland). Body weight and length were measured in 20 individuals of each prey species. The activity rate was assessed using a video-tracking system in 45 individuals because of a higher variation within individuals. Adults of each prey species were maintained at $4^{\circ} \mathrm{C}$ for $10 \mathrm{~min}$ to reduce activity. Then, after $1 \mathrm{~min}$ at room temperature $\left(21^{\circ} \mathrm{C}\right)$, each specimen was placed individually in the center of a glass Petri dish $(5.2 \mathrm{~mm}$ in diameter) and the activity was analysed for 20 min using a Computar ${ }^{\circledR}$ lens (H2Z0414C-MP, $f=4-8 \mathrm{~mm}$, F 1.4, 1/2", CCTV lens) mounted on a Basler ${ }^{\circledR}$ GigE HD Camera (acA1300-60gc with e2v EV76C560 CMOS sensor). The recording tool used was the Media Recorder 2.5 software (Noldus Media Recorder, 2013) and the Petri dishes were illuminated from below (negative contrast) using a computer screen placed horizontally with a full white Microsoft PowerPoint slide loaded. The Noldus Ethovision XT 11.5 software (Noldus, Spink, \& Tegelenbosch, 2001) was used to gather the mean velocity $(\mathrm{cm} / \mathrm{s})$ and the total time moving (s) of each individual. Three replicates for each species were video-recorded in five blocks of nine Petri dishes per block (45 tracks per species).

\section{7 | Data analysis}

\subsection{1 | Functional response assays}

Statistical analyses were performed using R software (R Core Team, 2018), based on the tools available from the "frair" package (Pritchard, 2017) and following Benhadi-Marín, Pereira, Barreales, Sousa, and Santos (2018). For each dataset we selected the type of functional response in four steps:

First, we fitted the number of prey killed during the time of the experiment to a generic type-I functional response model (a linear increase in attack rate with greater prey density) as:

$$
N_{\mathrm{e}} \sim a \times N_{0} \times T
$$

where $N_{e}$ represents the number of prey killed, $N_{0}$ represents the initial prey density, $a$ represents the attack rate (searching efficiency per time) and $T$ the duration of the experiment. For the datasets that did not fit the type-I response we followed Juliano (1989) to determine the shape of the functional response of the remaining cases by fitting a polynomial function with the generic form:

$$
\begin{aligned}
N_{\mathrm{e}} / N_{0}= & \exp \left(\beta_{0}+\beta_{1} N_{0}+\beta_{2} N^{2}{ }_{0} \ldots \beta_{z} N^{z}{ }_{0}\right) / 1 \\
& +\exp \left(\beta_{0}+\beta_{1} N_{0}+\beta_{2} N^{2}{ }_{0} \ldots \beta_{z} N^{z}{ }_{0}\right)
\end{aligned}
$$

where $N_{0}$ represents the initial prey densities and $N_{e}$ is the number of prey killed. The function frair_test provides the sign and $p$-values of the coefficients $\left(\beta_{1}\right.$ and $\beta_{2}$ ) used to select between type-II or type-III response.

A negative linear coefficient $\left(\beta_{1}\right)$ means a better adjustment to type-II functional response (the number of prey killed hyperbolically approaches to an asymptote which represent the maximum attack rate) in which case the most commonly used models are (a) the Holling's type-Il predator-prey function (for experiments with prey replacement) (Holling, 1959):

$$
N_{\mathrm{e}} \sim\left(a \times N_{0} \times T\right) / 1+\left(a \times N_{0} \times T_{\mathrm{h}}\right)
$$

where $N_{e}$ represents the number of prey killed, $a$ is the attack rate (searching efficiency per time), $N_{0}$ is the initial prey density, $T$ is the duration of the experiment and $T_{\mathrm{h}}$ is the handling time (time to attack, kill and eat each prey), and (b) the Rogers's type-Il decreasing prey function (for experiments without prey replacement, that is, prey depletion) (Rogers, 1972):

$$
N_{e} \sim N_{0}\left\{1-\exp \left[a\left(N_{e} \times T_{\mathrm{h}}-T\right)\right]\right\}
$$

where $N_{e}$ represents the number of prey killed, $N_{0}$ is the initial prey density, $a$ is the attack rate (searching efficiency per time), $T_{\mathrm{h}}$ is the handling time and $T$ the duration of the experiment. The fact that $N_{e}$ appears in both sides of the equation is because of lacking of prey replacement during the experiment and is solved using the Lambert's transcendental equation (Bolker, 2008).

A positive linear coefficient $\left(\beta_{1}\right)$ and a negative quadratic coefficient $\left(\beta_{2}\right)$ imply that the data fit a type-III functional response (the attack rate $[a]$ is a hyperbolic function of prey density) (see Juliano, 1989 ) in which case a scaling exponent on the attack rate (a) can be implemented as:

$$
a \sim b \times N_{0}{ }^{a}
$$

where $a$ is the attack rate, $b$ is a search coefficient, $N_{0}$ is the initial prey density, and as $q$ increases $(q \geq 0)$, the functional response becomes progressively sigmoid (Vucic-Pestic, Rall, Kalinkat, \& Brose, 2010). This applies for both the Holling's type-II predator-prey function (i.e., assuming prey replacement) and the Rogers's type-II decreasing prey function (not assuming prey depletion).

Secondly, once the type of functional response (type-II or type-III) was selected, we used the frair_fit function to fit the data. The frair_fit function fits non-linear predator-prey curves to integer data using the "Nelder-Mead" method for the selected functional response type estimating its parameters (e.g., attack rate $[a]$ and handling time $\left[T_{h}\right]$ in the case of a type-II response).

Thirdly, once estimated, the attack rate $(a)$ and handling time $\left(T_{\mathrm{h}}\right)$ were bootstrapped using the frair_boot function which resamples a previously fitted predator-prey functional response model and provides the $95 \%$ confidence intervals for each parameter. The whole 
empirical confidence interval for each curve was generated using the drawpoly function that draws a closed polygon delineated by the upper and lower edges given by frair_boot over the plotted curve.

Finally, the maximum attack rate $T / T_{h}$ (i.e., the maximum number of prey that can be attacked by a predator during the time interval considered) was estimated for each spider species as $24 / T_{\mathrm{h}}$ and its confidence intervals generated using the simaR library (Benhadi-Marín et al., 2018). In order to test the effect of additional prey species within the arenas, the multiple-prey functional response analysis was performed for each spider species as described for the single-prey functional responses considering $C$. capitata as target prey ignoring the other prey species, and then compared with the single-prey functional response assays through the confidence intervals.

\subsection{2 | Prey biomass suppression}

The prey biomass removed from the arenas of spiders was assessed by calculating the following parameters:

Spider weight gain = Final spider weight - Initial spider weight

Captured prey biomass $=\left(\right.$ Initial prey fresh weight $\left./ N_{0}\right)$

$$
\times \text { Number of prey killed }
$$

Consumed prey biomass $=$ Prey biomass removed from the arena

$$
\text { - Remains of captured prey weight }
$$

Metabolism $=$ Consumed prey biomass - Spider weight gain

Unexploited prey biomass = Captured prey biomass

$$
\text { - Consumed prey biomass }
$$

$\%$ Unexploited prey biomass $=($ Unexploited prey biomass $\times 100)$

$$
\text { /Captured prey biomass }
$$

The captured prey biomass, consumed prey biomass, metabolism (we assume the difference between the consumed prey biomass and the spider weight gain as the amount of resources spent in terms of metabolism) and spider weight gain were modelled for each spider species as a function of the initial prey density. For it, a series of linear and polynomial models were developed following Zuur, leno, Walker, Saveliev, and Smith (2009), giving the final models:

$$
\text { Spider weight gain } \sim \alpha+\beta \times N_{0}
$$

$$
\begin{aligned}
& \text { Captured prey biomass } \sim \alpha+\beta_{1} \times N_{0}+\beta_{2} \times N_{0}{ }^{2} \\
& \text { Consumed prey biomass } \sim \alpha+\beta_{1} \times N_{0}+\beta_{2} \times N_{0}{ }^{2} \\
& \text { Metabolism } \sim \alpha+\beta_{1} \times N_{0}+\beta_{2} \times N_{0}{ }^{2}
\end{aligned}
$$

$$
\text { Consumed prey biomass } \sim \alpha+\beta_{1} \times N_{0}+\beta_{2} \times N_{0}^{2}
$$

where $N_{0}$ is the initial prey density.
The percentage of unexploited prey biomass was modelled using a linear model in the case of $H$. rufipes, and a self-starting nonlinear model for A. cucurbitina and S. globosum as follows:

$$
\begin{gathered}
\text { UPBH } \sim \alpha+\beta_{1} \times N_{0} \\
\text { UPBA } \sim a /\left(1+\exp \left(\left(b-N_{0}\right) / c\right)\right) \\
\text { UPBS } \sim a /\left(1+\exp \left(\left(b-N_{0}\right) / c\right)\right)
\end{gathered}
$$

where $N_{0}$ is the initial prey density and UPBH, UPBA and UPBS correspond to the percentage of unexploited prey biomass of $H$. rufipes, A. cucurbitina and S. globosum, respectively.

Finally, percentage of unexploited prey biomass was compared between spider species using a one-way analysis of variance (ANOVA) followed by a post hoc multiple comparisons analysis.

\subsection{3 | Spider food preference}

The count of the number of individuals killed of each prey species was used to assess the spider's food preference by calculating D, a modification of the Ivlev's Electivity Index (Ivlev, 1961) proposed by Jacobs (1974) that is independent of the relative abundance of each food type at the initial food density. Using Pearre Jr. (1982) notation:

$$
D_{\mathrm{a}}=\left(a_{\mathrm{d}} \times e\right)-\left(a_{\mathrm{c}} \times d\right) /\left(a_{\mathrm{d}} \times e\right)+\left(a_{\mathrm{c}} \times d\right)-2 \times\left(a_{d} \times a_{\mathrm{c}}\right)
$$

were $a_{d}$ is the number of the killed individuals of the species "a", $d$ is the sum of the killed individuals of each species, $a_{c}$ is the initial number of the species "a" and e is the sum of the initial number of each species. $D$ ranges from -1 (prey type avoided) to +1 (prey type preferred) and it was calculated for each initial prey density and prey species and provided together with its SE. The food preference results (D) were pooled together for each spider and prey species along the different initial prey densities ( $n=60$ ), the mean and its 95\% confidence interval was calculated and for each spider-prey combination, a one sample Student's $t$-test $(p<.01)$ was used to check if $D$ was significantly different from zero (i.e., no-preference or avoidance for a prey species).

\section{8 | Prey functional traits}

The activity rate (AR) was calculated for each individual as the percentage of time moving corrected by the mean velocity:

$$
\begin{gathered}
\text { AR }=(\text { Time } \text { moving }(\mathrm{s}) \times 100 / \text { Total track duration }(\mathrm{s})) \\
\times \text { Mean velocity }(\mathrm{cm} / \mathrm{s})
\end{gathered}
$$

The prey biomass (PB), length (BL) and activity rate (AR) were compared between prey species using an ANOVA.

Finally, a post hoc multiple comparisons analysis was carried out to test for significant differences between prey species. 


\subsection{1 | Relationship between food preference and prey traits}

The link between food preference and the prey traits considered in this work was established through a distribution of the proportion of prey individuals representing each trait within each arena. A qualitative dichotomous partition of each trait was considered (e.g., lower vs. higher) according to the results obtained in the previous section; then, the proportion of individuals was assigned to each new trait category accounting for the initial amount of each prey species within the arenas. The proportion of individuals 3:1:1 (fly:moth:cricket) of the first initial prey density within each area during the multiple-prey experiment was used as reference. Finally, each branch of the distribution of traits was related to the electivity index and a category was assigned (from avoided to preferred) for each upstream combination of traits.

\section{3 | RESULTS}

\section{1 | Functional response assays}

The estimated parameters for the analyses of the empirical proportion of prey killed by A. cucurbitina and S. globosum fitted type-II functional response models when fed only on $\mathrm{C}$. capitata adults while $H$. rufipes fitted a type-I functional response model (Table 1).

During the single-prey experiment, $S$. globosum was the species that killed the lowest number of $C$. capitata adults at the end of the experiment followed by $A$. cucurbitina; $H$. rufipes killed the highest number of flies and the number of prey killed was statistically significantly different among the three spider species according to the $95 \%$ confidence intervals obtained for the curves (Figure 1a).

Considering the overlap of the $95 \%$ confidence intervals, the coefficients of attack rate (a) were significantly different among the species. A. cucurbitina showed the highest $a$ value followed by S. globosum and $H$. rufipes (Table 1). The estimated handling times $\left(T_{h}\right)$ of $A$. cucurbitina and S. globosum were not significantly different while the maximum attack rate $\left(T / T_{h}\right)$ of $A$. cucurbitina was significantly higher than that of $S$. globosum (Table 1).

When the three prey species were offered together, the results obtained for S. globosum also fitted a type-II functional response, whereas $H$. rufipes and $A$. cucurbitina switched their functional responses to type-II and type-I, respectively (Table 1 ).

In the presence of multiple prey species, $H$. rufipes killed significantly less $C$. capitata adult individuals at the end of the experiment when compared with the single-prey experiment (Figure $1 \mathrm{~b}$ ) and no significantly differences were observed for A. cucurbitina (Figure 1c). On the contrary, the number of flies killed by $S$. globosum was significantly higher (Figure 1d).

The estimated handling time for $\mathrm{H}$. rufipes was significantly higher than that of $S$. globosum during the multiple-prey experiment whereas the maximum attack rate was significantly lower (Table 1).

Comparing the coefficients of attack rate obtained in single- and multiple-prey experiments, the former was significantly higher than the latter in the case of $H$. rufipes, significantly lower for $A$. cucurbitina and was not significantly different for $S$. globosum (Table 1). However, the estimated handling time obtained for S. globosum significantly decreased and the maximum attack rate significantly increased (Table 1).

\section{2 | Prey biomass suppression}

The captured prey biomass, consumed prey biomass and metabolism of $H$. rufipes significantly increased as the initial prey density increased (Table 2 and Figure 2a). The prey biomass captured by S. globosum also significantly increased, and in both species the maximum values for these parameters were reached at the maximum initial prey density $(N=40$ ) (Table 2 and Figure 2a,c). The captured prey biomass, consumed prey biomass and metabolism of A. cucurbitina were also significantly affected by the initial prey density reaching a maximum $(159.730,96.113$ and $82.777 \mathrm{mg}$ ) at an initial prey density of $\approx 37, \approx 27$ and $\approx 26$ flies, respectively (Figure $2 b$ ). The weight gain of $S$. globosum was also significantly

TAB LE 1 Estimated parameters for the linear and logistic regression analysis of the number of prey killed against prey density for the three spider species studied in the single- and multiple-prey functional response experiments

\begin{tabular}{|c|c|c|c|c|c|c|c|c|}
\hline Modality & Predator & Estimate & $S E$ & $z$-value & $\operatorname{Pr}(>|z|)$ Type & $a(\mathrm{Cl})$ & $T_{h}(\mathrm{Cl})$ & Simulated $T / T_{h}(\mathrm{Cl})$ \\
\hline \multirow[t]{2}{*}{ SPS } & Haplodrassus rufipes & 0.845 & 0.0423 & $389.1^{\mathrm{F}}$ & $<0.001$ । & $0.031(0.028,0.034) c$ & - & - \\
\hline & Araniella cucurbitina & -0.080 & 0.007 & -11.037 & $<0.001$ & $0.179(0.143,0.225)$ a & $0.897(0.734,1.039)$ a & $26.674(26.311,27.038)$ a \\
\hline \multirow[t]{2}{*}{ MPS } & Haplodrassus rufipes & -0.046 & 0.005 & -8.562 & $<0.001$ II & $0.090(0.061,0.130) a *$ & $1.201(0.890,1.509)$ a & $22.272(21.824,22.743)$ a \\
\hline & Araniella cucurbitina & 0.064 & 0.031 & $424.1^{\mathrm{F}}$ & $<0.001$ । & $0.028(0.026,0.030) b^{*}$ & - & - \\
\hline
\end{tabular}

Different letters for $a, T_{\mathrm{h}}$ and simulated $T / T_{\mathrm{h}}$ mean significant differences between spider species within each experiment. Asterisks indicate statistical significant differences between parameters comparing the two types of experiments. $F$ indicates the $F$-value ( 1 degree of freedom) corresponding to the type-I functional response fitting model.

Abbreviations: $a$, coefficient of attack rate; $\mathrm{Cl}, 95 \%$ confidence interval; Estimate, coefficients derived from the models used to select between type-II and type-III type of functional response; MPS, multiple-prey experiment; SPS, single-prey experiment; Type: empirical response type; $T_{\mathrm{h}}$, estimated handling time. 

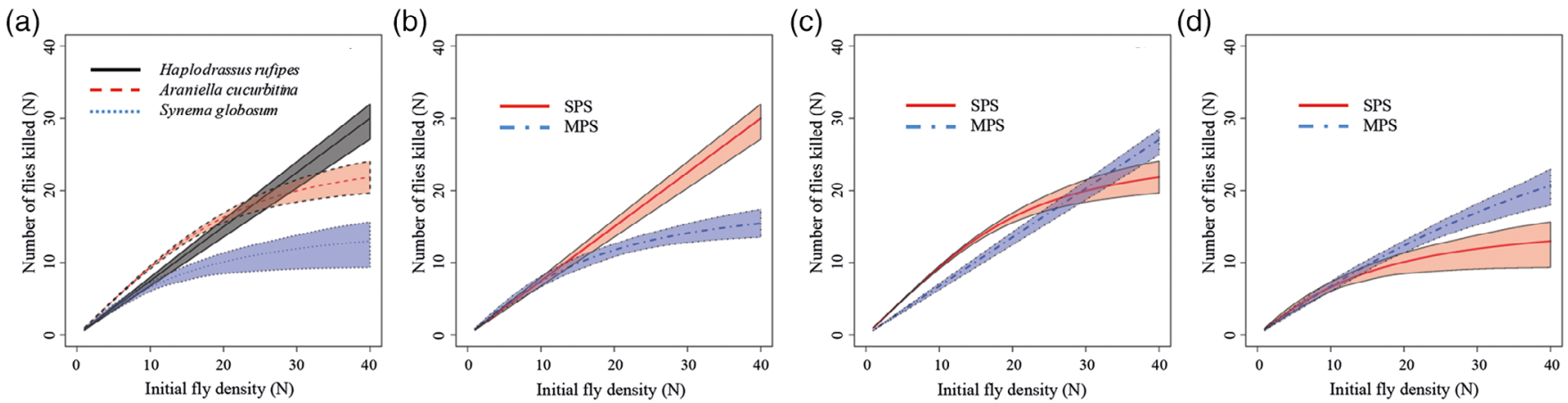

FIGURE 1 Functional response models obtained for Haplodrassus rufipes (ground runner), Araniella cucurbitina (orb weaver) and Synema globosum (ambusher) fed on Ceratitis capitata adults during 24-hr single-prey (non-choice) experiments (a), and functional response models obtained for single-prey species (SPS) experiments and for multiple-prey species (MPS) experiments with Haplodrassus rufipes (b), Araniella cucurbitina (c) and Synema globosum (d). In SPS experiments, only C. capitata adults were provided, and in MPS, C. capitata, Ephestia kuehniella and Acheta domesticus adults were provided together at ratios of 3:1:1, respectively. Thick lines represent the fitted values of data and the bands that surround them represent the limits of the $95 \%$ confidence interval of the empirical curves

affected by the initial prey density and the maximum value was obtained $(30.318 \mathrm{mg}$ ) at $\approx 31$ flies (Figure $2 \mathrm{c}$ ). On the contrary, there was no significant variation in the weight gain of $H$. rufipes and $A$. cucurbitina with the initial prey densities (Table 2 and Figure 2a,b). Also, the metabolism and consumed prey biomass of S. globosum were not significantly affected by the initial number of flies (Table 2 and Figure 2c).

The percentage of unexploited prey biomass (\%UPB) was not significantly different between spider species $(F=.361 ; \mathrm{df}=2,117$; $p=.698$ ) and did not significantly change with the initial prey density in the case of $H$. rufipes $(38.09 \%$ in average) $(F=.071 ; \mathrm{df}=1,58$; $p=.791$ ) (Figure $2 \mathrm{~d}$ ). On the contrary, this parameter varied significantly with the initial prey density for A. cucurbitina ( $a=67.789$, $p \leq .001 ; b=23.640, p=.016 ; c=13.848, p=.003$ ) and $S$. globosum $(a=52.0701, p \leq .001 ; b=5.5528, p=.001 ; c=1.1393, p=.158)$ reaching its maximum at different prey densities, 40 flies in the case of $A$. cucurbitina (\%UPB $=51.87 \%$ ) (Figure $2 \mathrm{e}$ ) and $\approx 10$ flies for S. globosum (\%UPB = 52.07\%) (Figure 2f).

TAB LE 2 Statistics of the models developed for the spider weight gain, captured prey biomass, consumed prey biomass and metabolism as a function of the initial prey density along the single prey species (Ceratitis capitata) functional response experiments

\begin{tabular}{|c|c|c|c|c|c|c|c|c|c|}
\hline Predator & Model & IV & Estimate & SE & $t$-value & $\operatorname{Pr}(>|t|)$ & Df & F-statistic & $\operatorname{Pr}(>F)$ \\
\hline \multirow{5}{*}{$\begin{array}{l}\text { Haplodrassus } \\
\text { rufipes }\end{array}$} & Spider weight gain & Initial fly density & 0.149 & 0.130 & 1.145 & 0.257 & 1 & $1.311(1,58)$ & 0.257 \\
\hline & Captured prey biomass & Initial fly density & 563.590 & 22.777 & 24.740 & $<0.001$ & 2 & $325.220(2,57)$ & $<0.001$ \\
\hline & \multirow[t]{2}{*}{ Consumed prey biomass } & Initial fly density & 376.862 & 22.821 & 16.514 & $<0.001$ & \multirow[t]{2}{*}{2} & \multirow[t]{2}{*}{$151.600(2,57)$} & \multirow[t]{2}{*}{$<0.001$} \\
\hline & & ${\text { (Initial fly density })^{2}}^{2}$ & 126.002 & 22.821 & 5.521 & $<0.001$ & & & \\
\hline & Metabolism & $(\text { Initial fly density })^{2}$ & 144.014 & 22.059 & 6.445 & $<0.001$ & 2 & $153.200(2,49)$ & $<0.001$ \\
\hline \multirow{4}{*}{$\begin{array}{l}\text { Araniella } \\
\quad \text { cucurbitina }\end{array}$} & Spider weight gain & Initial fly density & -0.051 & 0.120 & -0.422 & 0.674 & 1 & $0.179(1,58)$ & 0.674 \\
\hline & \multirow[t]{2}{*}{ Captured prey biomass } & Initial fly density & 356.165 & 22.303 & 15.970 & $<0.001$ & \multirow[t]{2}{*}{2} & \multirow[t]{2}{*}{$141.270(2,57)$} & \multirow[t]{2}{*}{$<0.001$} \\
\hline & & $(\text { Initial fly density })^{2}$ & -116.959 & 22.303 & -5.244 & $<0.001$ & & & \\
\hline & Consumed prey biomass & Initial fly density & 140.019 & 18.689 & 7.492 & $<0.001$ & 2 & $51.734(2,57)$ & $<0.001$ \\
\hline \multirow{5}{*}{$\begin{array}{l}\text { Synema } \\
\text { globosum }\end{array}$} & \multirow[t]{2}{*}{ Spider weight gain } & Initial fly density & 67.397 & 11.954 & 5.638 & $<0.001$ & \multirow[t]{2}{*}{2} & \multirow[t]{2}{*}{$22.157(2,55)$} & \multirow[t]{2}{*}{$<0.001$} \\
\hline & & $(\text { Initial fly density })^{2}$ & -35.258 & 11.508 & -3.064 & 0.003 & & & \\
\hline & Captured prey biomass & Initial fly density & 1.942 & 0.274 & 7.092 & $<0.001$ & 1 & $50.302(1,58)$ & $<0.001$ \\
\hline & $\begin{array}{l}\text { Consumed prey } \\
\text { biomass }\end{array}$ & Initial fly density & 0.575 & 0.201 & 2.860 & 0.006 & 1 & $8.181(1,58)$ & 0.006 \\
\hline & Metabolism & Initial fly density & 0.135 & 0.128 & 1.049 & 0.299 & 1 & $1.101(1,49)$ & 0.299 \\
\hline
\end{tabular}

Abbreviation: IV, independent variable. 


\section{3 | Spider food preference and prey traits}

The three spider species showed the same pattern in terms of food preferences (Figure 3a-c). The electivity index (D) was positive and significantly different from zero for $C$. capitata, negative and significantly different from zero for $A$. domesticus and did not differ significantly from zero for E. kuehniella (Table 3).

The activity rate was significantly different between the three prey species $(F=29.57 ; \mathrm{df}: 2,402 ; p<.001)$. The highest percentage of activity rate corresponded to $A$. domesticus whereas the lowest mobile prey was E. kuehniella (Figure $3 d$ ). The body length (BL) was also significantly different between the three prey species ( $F=303.270 ;$ df: 2,$57 ; p<.001)$ with $A$. domesticus being the longest one followed by $C$. capitata and finally $E$. kuehniella (Figure $3 e$ ). The prey biomass (PB) was significantly different between prey species; however, no significant differences were found between $C$. capitata and $E$. kuehniella, and $A$. domesticus was significantly heavier than the two previous species ( $F=140.120$; df: 2,$57 ; p<.001$ ) (Figure $3 f)$.

\subsection{Relationship between food preference and prey traits}

The first trait considered was the prey biomass and it was categorised as heavy prey (A. domesticus) and light prey (C. capitata and E. kuehniella) (Figures $3 f$ and 4 ); because there were $60 \%$ of C. capitata and $20 \%$ of $E$. kuehniella within the arenas, the light prey category represented $p=.6+.2=.8$ of the total prey density and thus the heavy prey ( $A$. domesticus) represented $p=.2$. Then, the prey length was divided downstream into medium-sized prey (E. kuehniella represented $25 \%$ of $.8=.2$ ) and small-sized prey (C. capitata represented $75 \%$ of $.8=$.6) (Figures $3 e$ and 4). Within prey length level, the heavy prey (A. domesticus) inherited its upstream proportion $p=.2$ and was categorised as long-sized prey (Figures $3 \mathrm{e}$ and 4). The last one trait considered was the activity rate. The former long-sized prey (A. domesticus) inherited its proportion $p=.2$ and was categorised as highly mobile prey (Figures $3 d$ and 4). The medium-sized prey (E. kuehniella) inherited its proportion (a)

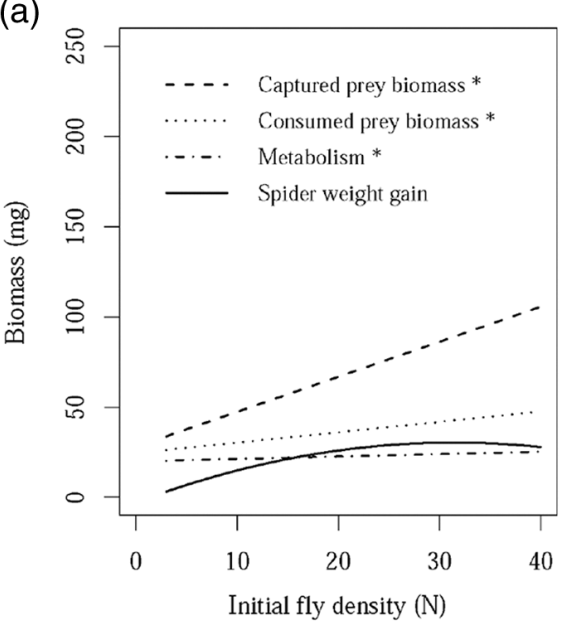

(c)

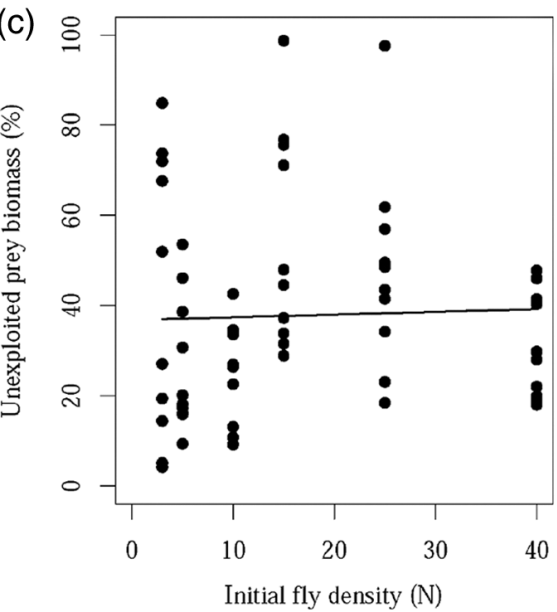

(b)



(d)

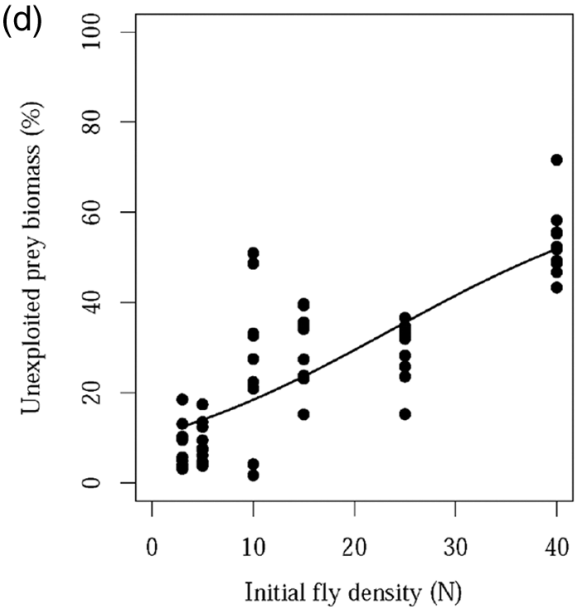

(c)
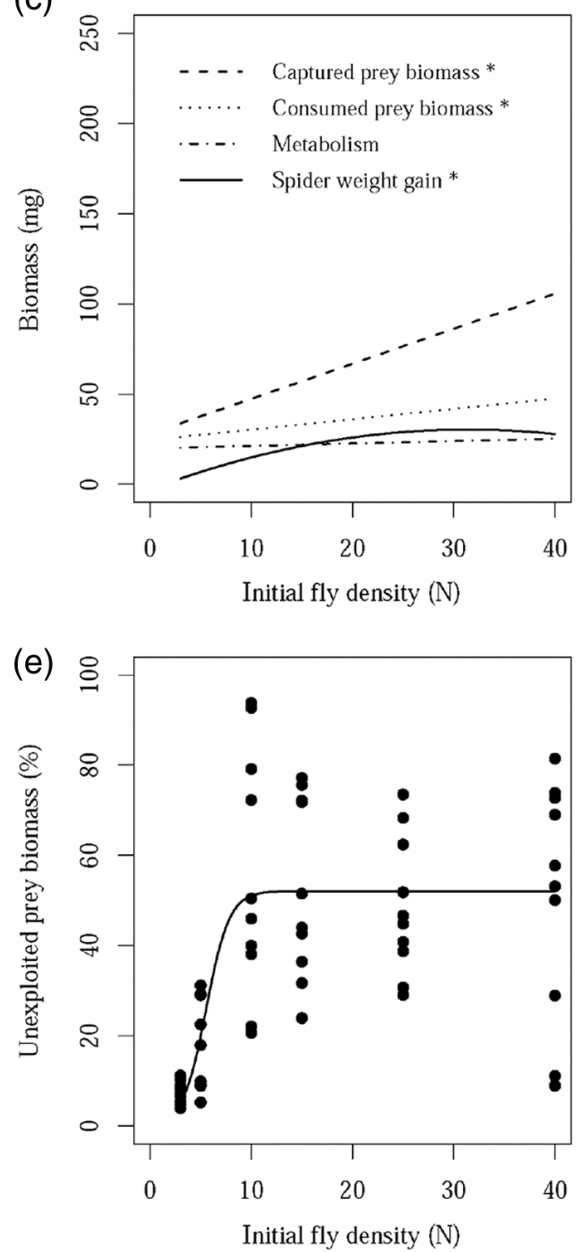

FIGURE 2 Relationship between the number of prey offered and the captured and consumed prey biomass, metabolism, spider weight gain (upper panels) and percentage of unexploited prey biomass of three functional groups of spiders fed for $24 \mathrm{hr}$ on differing densities of adults of Ceratitis capitata. Haplodrassus rufipes (ground hunter) (a and d), Araniella cucurbitina (orb-weaver) (b and e) and Synema globosum (ambusher) (c and f). Asterisks in (a), (b) and (c) indicate a slope significantly different from zero 

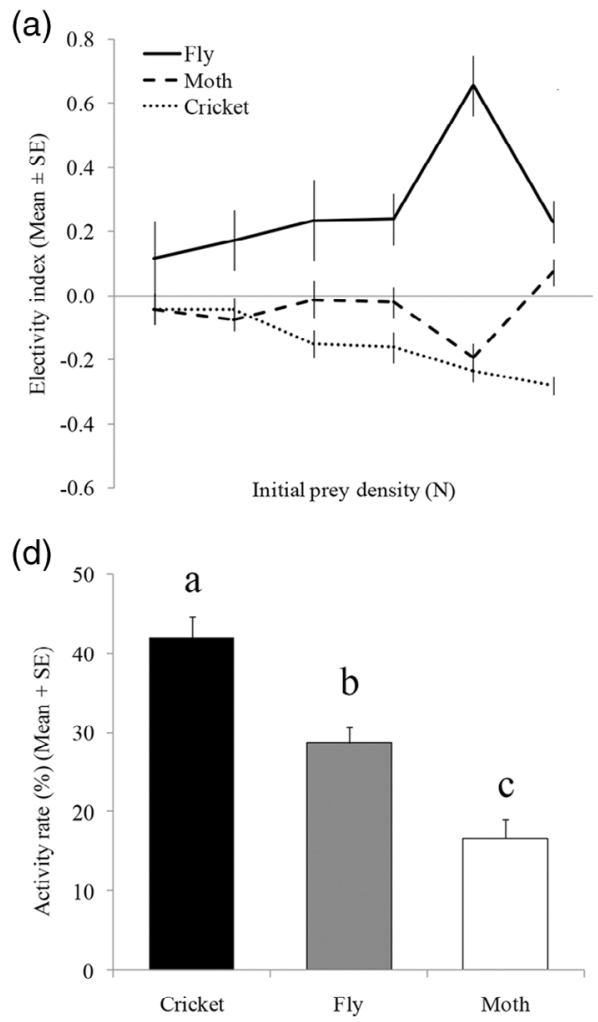

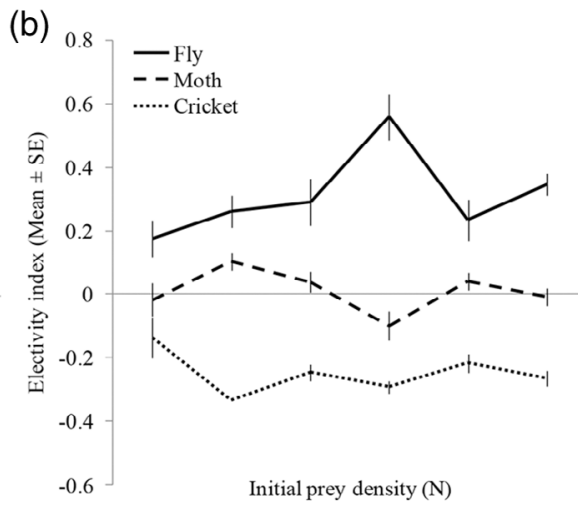

(e)

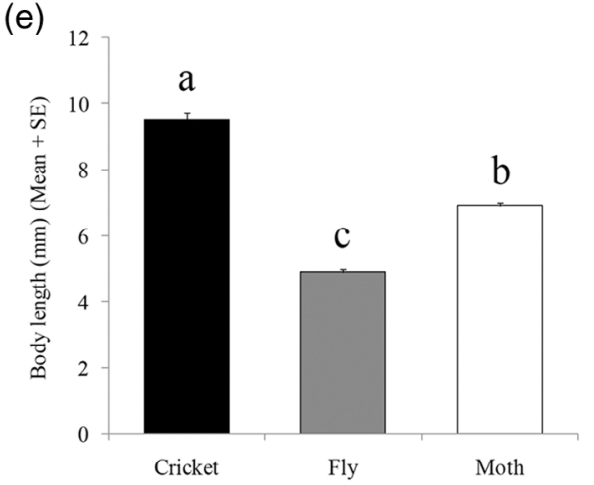

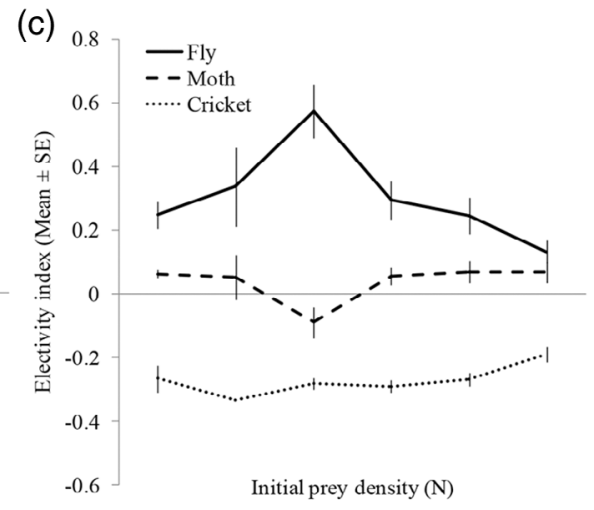

(f)

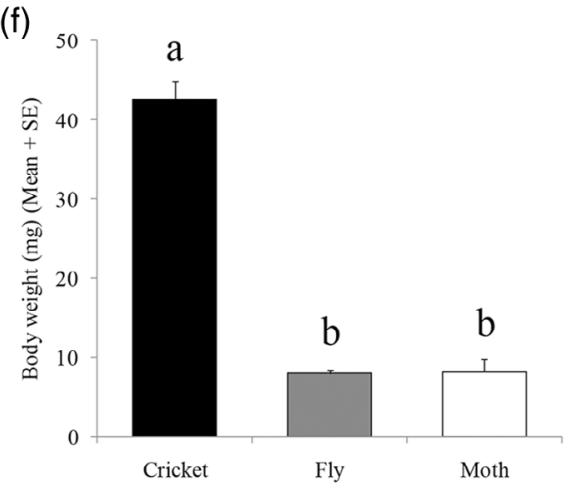

FIGURE 3 Feeding preference (electivity index, D) among three prey species (the fly Ceratitis capitata, the moth Ephestia kuehniella and the cricket Acheta domesticus) showed by three functional groups of spiders (upper panels), and functional traits of each prey species (lower panels). (a) Haplodrassus rufipes (ground runner). (b) Araniella cucurbitina (orb-weaver). (c) Synema globosum (ambusher). (d) activity rate. (e) body length. (f) prey biomass

$p=.2$ and was categorised as low mobile prey (Figures $3 d$ and 4) whereas the small-sized prey (C. capitata) inherited its proportion $p=.6$ and was categorised as moderately mobile prey (Figures $3 d$ and 4). Considering the values of the electivity index and each trait together, three prey classes were defined: (a) heavy, long-sized and highly mobile prey, (b) light, medium-sized and low mobile prey and (c) light, small-sized and moderately mobile prey corresponding to the avoided, occasionally consumed and preferred prey, respectively (Figure 4).

\section{4 | DISCUSSION}

In this work, each of the three guilds of spiders studied showed a different functional response on $C$. capitata, and the functional response significantly changed when alternative prey species were available. Our results correspond with those obtained by Benhadi-Marín et al. (2018) using C. capitata in non-choice laboratory experiments performed at $21^{\circ} \mathrm{C}$. At the highest prey density ( $N=40$ flies), BenhadiMarín et al. (2018) found that $A$. cucurbitina killed $20.75 \pm 2.75$
TABLE 3 Statistics of each $t$ test performed to compare the electivity indexes (D) calculated for assessing food preferences of the spider species Haplodrassus rufipes (HR) (ground runner), Araniella cucurbitina (AC) (orb weaver) and Synema globosum (SG) (ambusher) fed on each prey species used in the multiple-prey functional response experiments

\begin{tabular}{llrrrcr} 
Predator & Prey & t-value & df & Estimate & DCl & P \\
\hline HR & Ceratitis capitata & 5.882 & 59 & 0.274 & $0.181,0.368$ & $<.001$ \\
& Ephestia kuehniella & -2.094 & 59 & -0.046 & $-0.089,-0.002$ & .041 \\
& Acheta domesticus & -7.552 & 59 & -0.153 & $-0.194,-0.112$ & $<.001$ \\
\hline \multirow{2}{*}{ AC } & Ceratitis capitata & 10.494 & 59 & 0.311 & $0.252,0.370$ & $<.001$ \\
& Ephestia kuehniella & 0.564 & 59 & 0.010 & $-0.025,0.044$ & .575 \\
& Acheta domesticus & -15.594 & 59 & -0.248 & $-0.280,-0.216$ & $<.001$ \\
\hline \multirow{2}{*}{ SG } & Ceratitis capitata & 8.684 & 59 & 0.305 & $0.235,0.375$ & $<.001$ \\
& Ephestia kuehniella & 1.937 & 59 & 0.037 & $-0.001,0.074$ & .058 \\
& Acheta domesticus & -23.422 & 59 & -0.271 & $-0.295,-0.248$ & $<.001$ \\
\hline
\end{tabular}

Abbreviations: $\mathrm{DCl}, 95 \%$ confidence interval for the mean of $\mathrm{D}$; df, degrees of freedom; Estimate, mean of $D$ for the complete pool of samples $(n=60)$. 


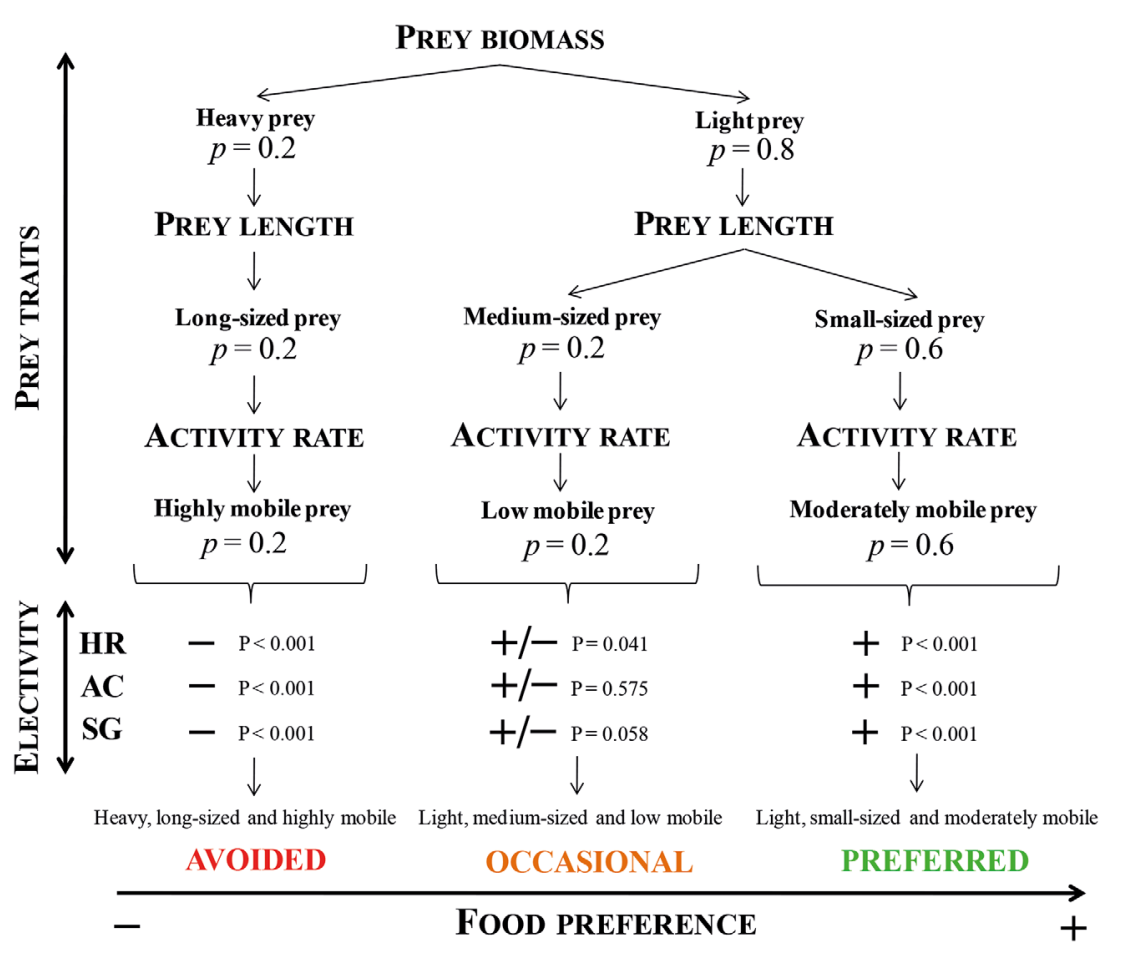

FIGURE 4 Relationship between prey traits, relative abundance, electivity index and food preference of three functional groups of spiders fed on three alternative prey species (Acheta domesticus, Ephestia kuehniella and Ceratitis capitata) during a series of multiprey functional response laboratory experiments. $p$ represents the proportion of individuals of each category within an arena. $P$ represents the $p$-values of a $t$-test performed to compare the electivity index with the null hypothesis (no preference). AC, Araniella cucurbitina (orb-weaver); HR, Haplodrassus rufipes (ground runner); SG, Synema globosum (ambusher) individuals (mean \pm standard deviation) and S. globosum $7.5 \pm 1.73$ individuals, whereas in this study, $21.10 \pm 4.97$ and $11.50 \pm 4.46$ individuals were killed by each species, respectively. Although we found a different functional response type for A. cucurbitina, our confidence intervals for both the attack rate and handling time of $S$. globosum overlapped with those obtained by Benhadi-Marín et al. (2018).

Regarding the multiple-prey experiments, our results clearly demonstrated that the presence of alternative prey can shift the predatory efficiency of a generalist predator on a target prey species. For the single-prey experiments, the most and the least efficient spider species against $C$. capitata were $H$. rufipes and $S$. globosum, respectively. However, opposite patterns were found when alternative prey species were available. In the presence of alternative prey species $H$. rufipes shifted from a type-I to a type-Il functional response killing approximately half of the flies at the maximum prey density, A. cucurbitina shifted from a type-ll to a type-I functional response killing significantly more flies at the highest prey density and S. globosum showed a type-II functional response in both experiments significantly increasing the number of flies killed at the highest prey density.

Few studies have addressed the switching behaviour in spiders and suggested that spiders can actually switch between alternative preys according to prey density (e.g., Harwood, Sunderland, \& Symondson, 2004; Provencher \& Coderre, 1987). Because our experimental design focused on keeping the proportion "target prey/alternative prey" constant, we did not directly test the switching effect. Because of the massive preference of all spiders for the most abundant prey (flies) during the multiple-prey experiments (especially at the highest prey density), it would be reasonable to think that the three species may switch; however, it is still unclear if it corresponds to active (because of changes on behaviour) or passive (because of a constant prey preference) switching (see Begon, Harper, \& Townsend, 1996; Gentleman, Leising, Frost, Strom, \& Murray, 2003; Vallina, Ward, Dutkiewicz, \& Follows, 2014).

We found a clear gradient on the change of the prey biomass captured by spiders along the increased prey density during the singleprey experiments. While the prey biomass captured by $H$. rufipes increased exponentially, A. cucurbitina reached a plateau at the highest prey densities and $S$. globosum showed a linear increase. In general, spiders kill more prey than that they consume (Mansour \& Heimbach, 1993); however, different guilds may handle differently their resources according to their nutritional requirements and hunting strategies. Although the amount of overkilling usually increases with prey density (Mansour \& Heimbach, 1993; Samu \& Bíró, 1993), our results did not support this correlation for $\mathrm{H}$. rufipes. As ground runner, $H$. rufipes actively pursue its prey and because of its high body size presumably needs a high amount of energy to hunt; however, we did not found a significant increase in the percentage of unexploited prey biomass towards the highest prey densities.

Multiple-prey capture could explain this lack of correlation, $H$. rufipes was observed to pursue and kill several prey items in the arena before consumption. According to Bailey (1985) multiple-prey captures should occur at high prey densities, when hungry predators (in our case starved spiders before the experiments) are exposed to high numbers of prey items during short periods (e.g., a high prey density within an experimental arena). It has been suggested that this behaviour could be derived from an attempt to increase the size of each meal, thus allowing the spider to feed less frequently (Williams, 1979). Because $H$. rufipes represent the longest body size among the three species of spiders tested, our results and observations agree 
with those made by Williams (1979) on the active hunter Dolomedes Latreille, 1804 (Pisauridae) both in the field and in laboratory supporting that multicapture is performed by bigger spiders that are capable to handle several small preys.

Because the density of alternative preys ( $E$. kuehniella and A. domesticus) proportionally increased across the increasing target prey densities ( $C$. capitata), changes on the functional response and predatory behaviour between the single- and multiple-prey experiments could be explained in terms of predator-prey encounter rates (Scharf, Ovadia, \& Bouskila, 2008; Smout et al., 2010). Because of the higher number of total prey items within the arenas in the multipleprey experiments (i.e., the same number of flies plus the alternative preys), the predator-prey encounter rate can increase when compared with the single-prey experiments.

Considering the preference of $\mathrm{H}$. rufipes for flies (especially at high prey densities), selecting each individual among an increased number of prey items can be more costly. The handling time includes the time necessary to pursue, subdue, feed and restart hunting (Holling, 1959), and in fact, the handling times of $\mathrm{H}$. rufipes increased from a theoretical zero (type-I response) during the single-prey experiments to $1.2 \mathrm{hr}$ during the multiple-prey experiments. Moreover, the spiders' functional response can be reduced, as we found for $\mathrm{H}$. rufipes, if the nutrient composition of the prey is far from the spider's intake target (Toft, 2013), which suggests that $C$. capitata could be an easy-to-catch but low-quality prey for this species.

In the case of A. cucurbitina (orb-weaver), the web most likely enhanced the chances to trap flies (especially within a closed environment such as an experimental arena) thus decreasing the handling time from $0.89 \mathrm{hr}$ to theoretically zero when multiple preys were available and significantly increasing its functional response. For this species, we found that the percentage of unexploited prey biomass reached its maximum at the maximum prey density. In this case, our results agree with the general assumption that partial consumption increases with prey density.

Araniella cucurbitina could be considered as an actual queueing predator (i.e., predators for which handling and capture prey are not mutually exclusive, see Juliano (1989) for details) because of the use of their sticky webs for hunting purposes. In fact, we observed several spiders handling and eating $C$. capitata while other flies were stacked still alive or wrapped in the web. In this sense of queueing prey, although spiders could develop aversion against certain types of abundant prey (Toft, 1997, 2013), orb-weavers may prioritise the highest quality prey to the head of the queue among the available prey (Cox \& Smith, 1961). Accordingly, a kind of preference could be achieved if $C$. capitata was a high-quality prey for A. cucurbitina. However, Provencher and Coderre (1987) found that the behaviour of the orb-weaver Tetragnatha laboriosa Hentz, 1850 (Tetragnathidae) in experimental arenas created a refuge for prey, as spiders occupied the upper part of the arenas while prey remained in the lower part. Because we found the same behaviour in A. cucurbitina, C. capitata was significantly more active than E. kuehniella, and A. domesticus mostly used the bottom of the arenas, the preference for flies could be artificial and still remains unclear for A. cucurbitina.
Synema globosum is a sit-and-wait predator. Ambusher predators can actually search while eating and while waiting empty handed (Lucas, 1985); however, we did not observe S. globosum searching for other prey items during the consumption period. Probably as a result of an increase of the encounter rate, S. globosum increased the number of $C$. capitata killed during the multiple-prey experiments significantly reducing its handling time from 1.43 to $0.514 \mathrm{hr}$. This behaviour could be because of partial consumption. Synema globosum presented its maximum of unexploited prey biomass at the lowest number of prey density among the three species of spiders studied in this work during the single-prey experiments; however, the amount of consumed prey biomass was not significantly affected by prey density. Because $S$. globosum captures its prey one by one, two reasons, not mutually exclusive, may explain the decrease of its handling time and the lack of a significant increase of the consumed prey biomass with prey density; on one hand, it could be because of a temporary filling of the foregut instead from satiation (Johnson et al., 1975), and on the other hand, the increased response could be carried out by the disturbance caused by a prey while the spider was handling another one, thus making the spider to release the former and capture the new prey as Haynes and Sisojević (1966) suggested for the ambusher Philodromus rufus Walckenaer, 1826 (Philodrmidae) when fed on Drosophila melanogaster Meigen, 1830 (Diptera: Drosophilidae) in laboratory.

Considering the prey preference and prey traits, the three functional groups of spiders studied in this work surprisingly showed the same pattern: the heavy, long-sized and highly mobile preys (crickets) were avoided; the light, medium-sized and low mobile preys (moths) were occasionally killed; and the light, small-sized and moderately mobile preys (flies) were preferred. However, the hunting behaviour and feeding parameters clearly differed according to each spider guild. In addition, it must be highlighted that another important prey trait could play a role in terms of prey selection by the spiders, the fact that A. domesticus, unlike the other two prey types used in the experiments, is a predator. Summarising, when different prey species were available, orb-weavers could be efficient predators against flying pests such as C. capitata because of their web device. This is of capital importance for biological control because orb-weaver spiders encompass cosmopolitan species (such as A. cucurbitina) frequently observed inhabiting crops (e.g., Mestre, Piñol, Barrientos, Cama, \& Espadaler, 2012) at different vertical strata including the canopy of trees, bushes and the herbaceous layer (Nentwig et al., 2018). On the other hand, flower-living ambushers such as $S$. globosum could help to reduce the population of pest flies that feed on pollen and/or nectar, whereas active ground hunters with a lower functional response on flies such as $H$. rufipes may also play an important role preying on soil-inhabiting life cycle stages of pests (e.g., crawling or digging larvae and teneral stages of dipteran pests).

Laboratory experiments based on a single predator-prey system may lead to a limited understanding of its functional response in the field and multiple-prey laboratory experiments have been strongly recommended (e.g., Smout et al., 2010). The consideration of different 
sources of noise in laboratory experiments including multiple prey availability, arenas of different size and variation in temperature is mandatory towards a more realistic evaluation of a predator functional response. Also, regardless of the type of experiment, it must be noticed that a reduced number of low-prey densities may lead to hide type-III functional responses. Although efforts have been made to assess the role of predator traits on the predation rates in agroecosystems (e.g., Rusch, Birkhofer, Bommarc, Smith, \& Ekbom, 2015), research focused on the body parameters of prey is required to disentangle the role of their traits in a context of biological control. Also, further research in terms of feeding parameters such as the amount of overkilling and prey switching is needed for a better understanding of the effectiveness of spiders as natural enemies as biological control agents.

\section{ACKNOWLEDGEMENTS}

This work was funded by Portuguese Foundation for Science and Technology (FCT) through the project EXCL/AGR-PRO/0591/2012 "Olive crop protection in sustainable production under global climatic changes: linking ecological infrastructures to ecosystem functions" and by the project ReNATURE - Valorization of the Natural Endogenous Resources of the Centro Region" funded by Centro 2020 (Centro-01-0145-FEDER-000007). Jacinto Benhadi-Marín is grateful to the Portuguese Foundation of Science and Technology for financial support through the Ph.D. grant SFRH/BD/97248/2013. This manuscript is part of Jacinto Benhadi-Marín's Ph.D. thesis.

\section{CONFLICT OF INTEREST}

The authors have no conflicts of interest to declare.

\section{ORCID}

Jacinto Benhadi-Marín (D) https://orcid.org/0000-0002-9804-4145

\section{REFERENCES}

Ajuria, H., \& Reader, T. (2014). Female-limited colour polymorphism in the crab spider Synema globosum (Araneae: Thomisidae). Biological Journal of the Linnean Society, 113(2), 368-383.

Altieri, M. A. (1999). The ecological role of biodiversity in agroecosystems. Agriculture, Ecosystems and Environment, 74, 19-31.

Bailey, P. C. E. (1985). 'A prey in the hand', multi-prey capture behaviour in a sit-and-wait predator, Ranatra dispar (Heteroptera: Nepidae), the water stick insect. Journal of Ethology, 3, 105-112.

Begon, M., Harper, J. L., \& Townsend, C. R. (1996). Ecology: individuals, populations and communities. In Bioscience (3rd ed.). Oxford, England: Blackwell Science Ltd.

Benhadi-Marín, J., Pereira, J. A., Barreales, D., Sousa, J. P., \& Santos, S. A. P. (2018). A simulation-based method to compare the pest suppression potential of predators: A case study with spiders. Biological Control, 123, 87-96.

Bolker, B. (2008). Ecological models and data in R (p. 408). Princeton, NJ: Princeton University Press.
Cardoso, P., Pekár, S., Jocqué, R., \& Coddington, J. A. (2011). Global patterns of guild composition and functional diversity of spiders. PLoS One, 6(6), e21710.

Chan, K., Boutin, S., Hossie, T. J., Krebs, C. J., O'Donoghue, M., \& Murray, D. L. (2017). Improving the assessment of predator functional responses by considering alternate prey and predator interactions. Ecology, 98(7), 1787-1796.

Cox, D. R., \& Smith, W. L. (1961). Queues. London: Chapman \& Hall.

Dinis, A. M., Pereira, J. A., Benhadi-Marín, J., \& Santos, S. A. P. (2016). Feeding preferences and functional responses of Calathus granatensis and Pterostichus globosus (Coleoptera: Carabidae) on pupae of Bactrocera oleae (Diptera: Tephritidae). Bulletin of Entomological Research, 106(6), 701-709.

Gentleman, W., Leising, A., Frost, B., Strom, S., \& Murray, J. (2003). Functional responses for zooplankton feeding on multiple resources: A review of assumptions and biological dynamics. Deep-Sea Research II, $50,2847-2875$.

Harwood, J. D., Sunderland, K. D., \& Symondson, W. O. (2004). Prey selection by linyphiid spiders: Molecular tracking of the effects of alternative prey on rates of aphid consumption in the field. Molecular Ecology, 13(11), 3549-3560.

Hassanzadeh-Avval, M., Sadeghi-Namaghi, H., \& Fekrat, L. (2018). Prey preference and prey switching in Anthocoris minki Dohrn (Hemiptera: Anthocoridae). Journal of Asia-Pacific Entomology, 21, 1116-1121.

Haynes, D. L., \& Sisojević, P. (1966). Predatory behavior of Philodromus rufus Walckenaer (Araneae: Thomisidae). The Canadian Entomologist, 98(2), 113-133.

Holling, C. S. (1959). The components of predation as revealed by a study of small-mammal predation of the European pine sawfly. The Canadian Entomologist, 91(5), 293-320.

Ivlev, V. S. (1961). Experimental ecology of the feeding of fishes (p. 302). New Haven, CT: Yale University Press.

Jacobs, J. (1974). Quantitative measurement of food selection: A modification of the forage ratio and Ivlev's electivity index. Oecologia, 14(4), 413-417.

Jeschke, J. M., Kopp, M., \& Tollrian, R. (2002). Predator functional responses: Discriminating between handling and digesting prey. Ecological Monographs, 72, 95-112.

Johnson, D. M., Akre, B. G., \& Crowley, P. H. (1975). Modeling arthropod predation: Wasteful killing by damselfly naiads. Ecology, 56, 1081-1093.

Juliano, S. A. (1989). Queueing models of predation and the importance of contingent behavioural choices for optimal foragers. Animal Behaviour, 38, 757-770.

Lucas, J. R. (1985). Partial prey consumption by antlion larvae. Animal Behaviour, 33, 945-958.

Marc, P., Canard, A., \& Ysnel, F. (1999). Spiders (Araneae) useful for pest limitation and bioindication. Agriculture, Ecosystems \& Environment, 74, 229-273.

Mansour, F., \& Heimbach, U. (1993). Evaluation of lycosid, micryphantid and linyphiid spiders as predators of Rhopalosiphum padi (Hom.: Aphididae) and their functional response to prey density-laboratory experiments. Entomophaga, 38(1), 79-87.

Mestre, L., Piñol, J., Barrientos, J. A., Cama, A., \& Espadaler, X. (2012). Effects of ant competition and bird predation on the spider assemblage of a citrus grove. Basic and Applied Ecology, 13, 355-362.

Murdoch, W. W. (1969). Switching in general predators: Experiments on predator specificity and stability of prey populations. Ecological Monographs, 39(4), 335-354.

Nentwig, W., Blick, T., Gloor, D., Hänggi, A., \& Kropf, C. (2018). Spiders of Europe. Available at www.araneae.unibe.ch. Version 01.2018.

Noldus Media Recorder. (2013). Retrieved from http://www.noldus.com/ human-behavior-research/products/media-recorder-0.

Noldus, L. P. J. J., Spink, A. J., \& Tegelenbosch, R. A. J. (2001). EthoVision: A versatile video tracking system for automation of behavioral 
experiments. Behavior Research Methods, Instruments, \& Computers, 33 (3), 398-414.

Pearre, S., Jr. (1982). Estimating prey preference by predators: Uses of various indices, and a proposal of another based on $\chi^{2}$. Canadian Journal of Fisheries and Aquatic Sciences, 39, 914-923.

Pekár, S. (2005). Predatory characteristics of ant-eating Zodarion spiders (Araneae: Zodariidae): Potential biological control agents. Biological Control, 34, 196-203.

Pritchard, D. (2017). frair: Tools for Functional Response Analysis. R package version 0.5.100. Available at https://CRAN.R-project.org/package= frair.

Provencher, L., \& Coderre, D. (1987). Functional responses and switching of Tetragnatha laboriosa Hentz (Araneae: Tetragnathidae) and Clubiona pikei Gertsh (Araneae: Clubionidae) for the aphids Rhopalosiphum maidis (Fitch) and Rhopalosiphum padi (L.) (Homoptera: Aphididae). Environmental Entomology, 16(6), 1305-1309.

R Core Team. (2018). R: A language and environment for statistical computing. Vienna, Austria: R Foundation for Statistical Computing. Available at http://www.R-project.org

Rogers, D. (1972). Random search and insect population models. Journal of Animal Ecology, 41, 369-383.

Rusch, A., Birkhofer, K., Bommarc, R., Smith, H. G., \& Ekbom, B. (2015). Predator body sizes and habitat preferences predict predation rates in an agroecosystem. Basic and Applied Ecology, 16, 250-259.

Samu, F., \& Bíró, Z. (1993). Functional response, multiple feeding and wasteful killing in a wolf spider (Araneae: Lycosidae). European Journal of Entomology, 90, 471-476.

Scharf, I., Ovadia, O., \& Bouskila, A. (2008). Prey encounter rate by predators: Discussing the realism of grid-based models and how to model the predator's foraging mode: A reply to Avgar et al. The American Naturalist, 172(4), 596-598.

Smout, S., Asseburg, C., Matthiopoulos, J., Fernández, C., Redpath, S., Thirgood, S., \& Harwood, J. (2010). The functional response of a generalist predator. PLoS One, 5(5), e10761.

Solomon, M. E. (1949). The natural control of animal populations. Journal of Animal Ecology, 18, 1-35.

Thomas, M. C., Heppner, J. B., Woodruff, R. E., Weems, H. V., Steck, G. J., \& Fasulo, T. R. (2010). Featured creatures. In Ceratitis capitata (Wiedemann) (Insecta: Diptera: Tephritidae). Gainesville, Florida: Entomology \& Nematology Department, University of Florida Available at http://entnemdept.ufl.edu/creatures/fruit/mediterranean_ fruit_fly.htm\#top

Toft, S. (1997). Acquired food aversion of a wolf spider to three cereal aphids: Intra- and interspecific effects. Entomophaga, 42, 63-69.

Toft, S. (2013). Nutritional aspects of spider feeding. In W. Nentwig (Ed.), Spider Ecophysiology. Berlin, Heidelberg: Springer.

Turnbull, A. L. (1973). Ecology of true spiders (Araneomorphae). Annual Review of Entomology, 18, 305-348.

Uetz, G. W., Halaj, J., \& Cady, A. (1999). Guild structure of spiders in major crops. The Journal of Arachnology, 27, 270-280.

Vallina, S. M., Ward, B. A., Dutkiewicz, S., \& Follows, M. J. (2014). Maximal feeding with active prey-switching: A kill-the-winner functional response and its effect on global diversity and biogeography. Progress in Oceanography, 120, 93-109.

Vucic-Pestic, O., Rall, B. C., Kalinkat, G., \& Brose, U. (2010). Allometric functional response model: Body masses constrain interaction strengths. Journal of Animal Ecology, 79, 249-256.

Weldon, C. (2014). Ceratitis capitata (Mediterranean fruit fly). In Invasive Species Compendium. Detailed coverage of invasive species threatening livelihoods and the environment worldwide. Wallingford, England: CAB International. Available at https://www.cabi.org/isc/datasheet/12367

Williams, D. S. (1979). The feeding behaviour of New Zealand Dolomedes species (Araneae: Pisauridae). New Zealand Journal of Zoology, 6, 95-105.

Zuur, A., leno, E. N., Walker, N., Saveliev, A. A., \& Smith, G. M. (2009). Mixed effects models and extensions in ecology with $R$ (p. 574). New York, NY: Springer.

How to cite this article: Benhadi-Marín J, Pereira JA, Sousa JP, Santos SAP. Functional responses of three guilds of spiders: Comparing single- and multiprey approaches. Ann Appl Biol. 2019;1-13. https://doi.org/10.1111/aab.12530 